\title{
Role of Polyphosphate in Amyloidogenic Processes
}

\author{
Justine Lempart and Ursula Jakob \\ Department of Molecular, Cellular and Developmental Biology, University of Michigan, Ann Arbor, \\ Michigan 48109 \\ Correspondence: ujakob@umich.edu
}

\begin{abstract}
Polyphosphate (polyP), an extremely simple polyanion, has long been known to be involved in a variety of different cellular processes, ranging from stress resistance, biofilm formation, and virulence in bacteria to bone mineralization, blood clotting, and mammalian target of rapamycin (mTOR) signaling in mammalian organisms. Our laboratory recently discovered a completely unexpected role of polyP as a stabilizing scaffold for $\beta$-sheet-containing proteinfolding intermediates. This realization led us to investigate the effects of polyP on amyloidogenic processes and the novel concept that polyP might play a role in neurodegenerative diseases. In this review, we will summarize recent results that show that polyP is a physiological modifier that accelerates amyloid fiber formation, alters fiber morphology, and protects cells against amyloid toxicity. We will review the current knowledge on the distribution, levels, and roles of polyP in the mammalian brain, and discuss potential mechanisms by which polyP might ameliorate amyloid toxicity.
\end{abstract}

norganic polyphosphate (polyP), a linear arrangement of orthophosphate units covalently linked via phosphoanhydride bonds, has been around for billions of years (Kulaev and Vagabov 1983; Wood and Clark 1988). First identified in 1888 by the German scientist Leo Liebermann, polyP initially received very little attention (Baev et al. 2016). Based on its chemical structure, it was presumed that polyP serves as an inorganic phosphate $\left(\mathrm{P}_{\mathrm{i}}\right)$ reservoir, metal chelator, and/or buffer system in cells (Fig. 1). However, it took nearly 100 years until the real multifunctionality of polyP became known. Arthur Kornberg was, in large part, responsible for the renewed interest in polyP. Kornberg and his team not only showed that polyP is universally present in prokaryotic and eukaryotic species but, even more importantly, identified the enzymatic systems responsible for polyP biosynthesis and degradation in bacteria (Kornberg et al. 1956, 1999; Akiyama et al. 1993; Baldwin 2008). This discovery allowed first phenotypic studies with mutant strains lacking the polyP-synthesizing enzyme polyphosphate kinase PPK and revealed that polyP plays a multitude of different roles in bacteria, ranging from motility and biofilm formation to virulence and stress resistance (Fig. 1) (Kornberg et al. 1999; Rashid et al. 2000a; Rao et al. 2009; Docampo et al. 2011; Kulakovskaya et al. 2012). Although no polyP-synthesizing machinery has been identified in higher eukaryotes as of yet (Azevedo and Saiardi 2014), the

Editors: Richard I. Morimoto, F. Ulrich Hartl, and Jeffery W. Kelly

Additional Perspectives on Protein Homeostasis available at www.cshperspectives.org

Copyright (C) 2019 Cold Spring Harbor Laboratory Press; all rights reserved; doi: 10.1101/cshperspect.a034041

Cite this article as Cold Spring Harb Perspect Biol 2019;11:a034041 
J. Lempart and U. Jakob

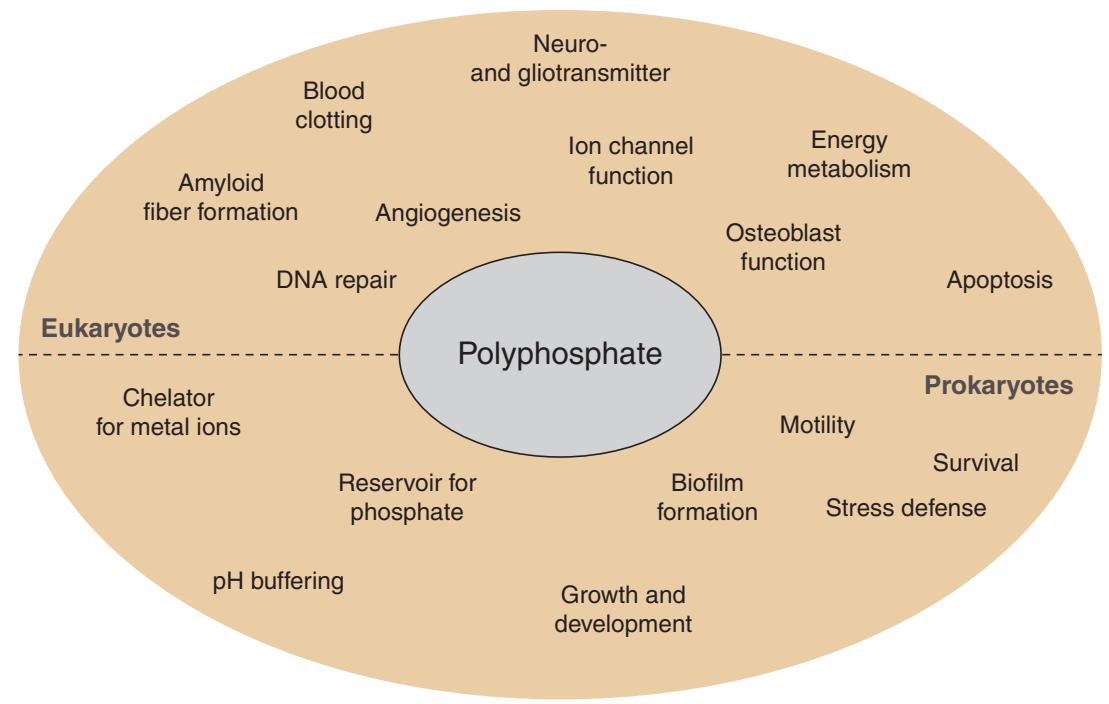

Figure 1. Polyphosphate (polyP)-associated processes in prokaryotes and eukaryotes.

function of polyP in eukaryotes appears to be similarly wide and seemingly mechanistically unrelated. polyP has been shown to be involved in processes related to cellular energy homeostasis (Abramov et al. 2007; Wang et al. 2016), blood clotting (Smith et al. 2006, 2010; Montilla et al. 2012; Morrissey et al. 2012), inflammation (Müller et al. 2009; Morrissey et al. 2012), apoptosis and permeability transition pore (PTP) formation (Abramov et al. 2007; Seidlmayer et al. 2012), osteoblast function (Kawazoe et al. 2004), DNA repair and nuclear transcription (Jimenez-Nunez et al. 2012; Bru et al. 2017), ion channel function (Kim and Cavanaugh 2007; Zakharian et al. 2009; Paulsen et al. 2015), and cell signaling in the mammalian brain (Holmström et al. 2013). Many excellent reviews have been dedicated to these various aspects of polyP function (Kornberg et al. 1999; Brown and Kornberg 2004; Kampinga 2014; Baev et al. 2016; Wang et al. 2016). In this review, we will therefore focus primarily on the most recent discovery that polyP serves as a physiologically relevant modifier of amyloidogenic processes and protects neurons against the toxic effects of disease-related amyloids (Cremers et al. 2016; Müller et al. 2017). These results, together with previous findings that polyP levels in the brain decrease with age (Lorenz et al. 1997), warrants the exploration of polyP as a novel player in age-related neurodegenerative diseases, such as Alzheimer's disease (AD) or Parkinson's disease (PD).

\section{POLYPHOSPHATE-A NOVEL PROTEIN- STABILIZING SCAFFOLD}

Interaction of polyP with Nonamyloidogenic Proteins

It is reasonable to assume that some of the reported polyP functions (Fig. 1) are either directly or indirectly linked to the energy-rich, metalchelating, and/or pH-buffering nature of polyP. However, recent studies from our laboratory revealed an additional and quite unexpected activity of the polyanion that could not be directly explained by its physicochemical properties. We found that polyP, whose endogenous levels have long been known to increase with proteotoxic stress conditions, such as heat shock or oxidative stress (Akiyama et al. 1992), interacts with protein unfolding intermediates and acts as a stabilizing scaffold to protect them against irreversible protein aggregation both in vitro and in vivo (Gray et al. 2014). This activity put polyP into the same category as stress-induced, protein-based chaperones, which increase in levels or activity during stress conditions to prevent 
irreversible protein aggregation (Feder and Hofmann 1999). In vitro studies, using a number of different purified proteins, showed that polyP binding to protein unfolding intermediates dramatically increases their thermal stability and maintains their solubility even on incubation at near-boiling temperatures (Yoo et al. 2018). Subsequent cooling in the presence of ATP-dependent chaperone systems promoted the refolding of the polyP client proteins, indicating that polyP maintains its bound proteins in a refolding-competent conformation. In vivo experiments confirmed these in vitro results and showed that $\Delta p p k$ strains show extensive stressinduced protein aggregation despite their attempts to compensate for the lack of polyP with the overexpression of common heat shock proteins (Gray et al. 2014; Yoo et al. 2018). These results helped to explain polyP's protective function under proteotoxic stress conditions, and suggested that polyP constitutes one of the earliest members of the cellular proteostasis network (Gray et al. 2014).

Structural analysis of the complexes formed between polyP and thermally unfolding proteins, such as lactate dehydrogenase, revealed the formation of small, soluble microaggregates, highly enriched in $\beta$-sheet structures and able to bind the amyloid-interacting dye thioflavin $\mathrm{T}$ (Yoo et al. 2018). Given that many of the polyPbinding partners are predominantly $\alpha$-helical in their native conformation, these results suggested that polyP binding either induces secondary structure changes or stabilizes emerging $\beta$-sheet structures. Because polyP does not noticeably interact with native proteins, we prefer the second scenario, and propose that polyP interacts with $\beta$-sheet structures that transiently accumulate on the protein unfolding pathway. Given the highly negative charge of polyP, it is tempting to assume that polyP binding increases the solubility of the proteins and the interactions are of ionic nature. However, it remains an outstanding question and will require high-resolution studies to figure out whether polyP interacts with proteins via their charged side chains or binds to the backbone of $\beta$-sheet structures. The latter would explain the promiscuity of interactions and the ability of polyP to stabilize a number of unrelated proteins in an amyloid-like $\beta$-sheet conformation (Gray et al. 2014; Yoo et al. 2018).

Interaction of polyP with Amyloidogenic Proteins In Vitro

The ability of polyP to bind to and stabilize $\beta$-sheet-rich secondary structures motivated us to study the effects of polyP on amyloid fibril formation. This was a particularly intriguing aspect because polyP has long been known to enhance fibrin clot structure during blood clotting in mammals (Smith and Morrissey 2008) and stimulate bacterial biofilm formation (Rashid et al. 2000b), processes that both involve the fiber formation of functional amyloids (Taglialegna et al. 2016).

Amyloid fiber formation is triggered by the conversion of soluble unstructured or $\alpha$-helical proteins into association-competent $\beta$-rich monomers (Eichner and Radford 2011), which assemble into cross- $\beta$-sheet oligomers, protofibrils, and mature fibrils (Fig. 2) (Soto 2003). In bacteria, the amyloidogenic proteins involved in biofilm formation (e.g., CsgA in Escherichia coli) are typically unstructured until they reach the cell surface, where they associate into stable, detergent, and protease-resistant cross- $\beta$-sheet fibrils (i.e., Curli) and form an integral part of the biofilm matrix (Hufnagel et al. 2013). Kornberg's early phenotypical studies using $\Delta p p k$ strains revealed that polyP-deficient bacteria form biofilms significantly more slowly than do wild-type strains (Rashid et al. 2000b). This phenotype was thought to be a result of a defect in quorum sensing. However, our studies showed that polyP directly affects biofilm formation by accelerating the conformational rearrangement of the amyloidogenic protein CsgA into cross- $\beta$-sheet fibers (Cremers et al. 2016). Moreover, supplementation of polyP into the media of $\Delta p p k$ mutants rescued CsgA fibril formation and restored the biofilm defect (Cremers et al. 2016). Unresolved thus far is whether polyP binds to unstructured CsgA and induces formation of the association-competent $\beta$-sheet protein, or whether polyP captures and stabilizes $\beta$-sheet-containing $\operatorname{CsgA}$, which transiently 
J. Lempart and U. Jakob

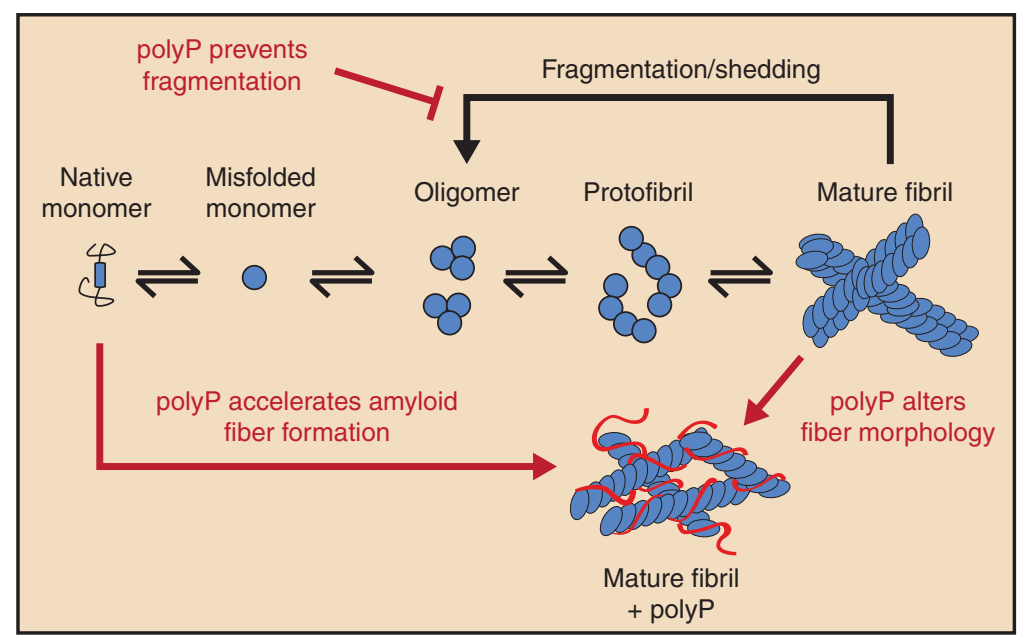

Figure 2. Influence of polyphosphate ( polyP) on amyloid fiber formation. Soluble unfolded or $\alpha$-helical amyloid monomers undergo structural rearrangements to adopt $\beta$-sheet-rich structures, which associate into oligomers and protofibrils. Eventually, mature fibrils form and are prone to fragmentation and shedding. polyP accelerates amyloid fiber formation, alters the fiber morphology, and stabilizes the mature fibers.

emerge from the unfolded state. In either case, these results explain at least one mechanism by which polyP increases the rate of biofilm formation in pathogenic bacteria (Rashid et al. 2000b; Chen et al. 2002), and makes the development of PPK inhibitors an important goal to treat biofilm-forming bacteria, which are involved in persistent infections (Dahl et al. 2017).

Curli fibrils in bacterial biofilm display all the characteristics of classical disease-associated amyloid fibrils (Hufnagel et al. 2013). Indeed, follow-up studies from our laboratory revealed that polyP significantly accelerates the fiber formation of $\alpha$-synuclein, the peptide associated with the pathology of $P D$, as well as $A \beta$ and Tau, amyloidogenic peptides associated with the pathology of $\mathrm{AD}$ (Cremers et al. 2016). The degree to which polyP accelerates formation of some of these fibrils is truly exceptional, for instance, TauK19, a shorter variant of Tau that forms fibrils more rapidly ( $\left.\mathrm{T}_{1 / 2}: 24-36 \mathrm{~h}\right)$ than full-length Tau $\left(\mathrm{T}_{1 / 2}>9 \mathrm{mo}\right)$ forms fibrils with a $\mathrm{T}_{1 / 2}<5 \mathrm{~min}$ when incubated in the presence of physiological amounts and chain lengths of polyP (Cremers et al. 2016). Moreover, both fulllength Tau, as well as very low, physiologically relevant concentrations of $\alpha$-synuclein and $A \beta$, which do not fibrillate in a reasonable timeframe in vitro, were found to form fibrils within a couple of days in the presence of polyP (Cremers et al. 2016). This effect was shown to be chainlength dependent with longer polyP chains $\left(>60 \mathrm{P}_{\mathrm{i}}\right)$ being disproportionally more effective than shorter-chain polyPs $\left(<14 \mathrm{P}_{\mathrm{i}}\right)$. These results suggested that polyP chains are able to nucleate fibril formation, presumably by bringing together multiple monomers, whose increased local concentrations accelerate fibril formation. More detailed analysis of $\alpha$-synuclein fibers formed in the presence of polyP revealed that the fibers are significantly less effective in seeding $\alpha$-synuclein fibrillation, about $30 \%$ more stable toward molecular disassembly (i.e., shedding), and less protease resistant than fibers formed without polyP (Cremers et al. 2016). Finally, the morphology of fibrils formed in the presence of polyP was distinctly different. Whereas $\alpha$-synuclein fibers formed in the absence of polyP consist of two single protofilaments twisted around each other in a distinct helix (Guerrero-Ferreira et al. 2018), fibers formed in the presence of polyP are significantly thinner and lack the characteristic twisted structure (Cremers et al. 2016). These results 
also agree with recent studies of platelet-derived polyP, which showed that polyP elicits structural changes in fibrin that generate shorter protofibrils with reduced stiffness and produce a fibrin network with increased knotted regions, which are polyP and fibrin rich (Whyte et al. 2016).

\section{POLYPHOSPHATE IN THE MAMMALIAN BRAIN}

Levels of polyP in the Mammalian Brain

Arthur Kornberg was the first to study polyP levels in different mammalian tissues (Kumble and Kornberg 1995). According to his studies, the highest polyP concentrations in rats are found in the brain $\left(25-120 \mu \mathrm{M}\right.$ per $\left.\mathrm{P}_{\mathrm{i}}\right)$ and the liver $\left(22-42 \mu \mathrm{M}\right.$ per $\mathrm{P}_{\mathrm{i}}$ ) (Gabel and Thomas 1971; Kumble and Kornberg 1995). Although the mammalian polyP-synthesizing machinery itself has yet to be identified, good evidence exists that polyP levels are directly linked to cellular respiration (Baev et al. 2016; Wang et al. 2016). This conclusion is based on studies with both intact astrocytes and isolated mitochondria in which interference with either the $\mathrm{F}_{1} \mathrm{~F}_{0}$-ATPsynthase, the membrane potential, or the electron transport chain was found to lead to dramatically reduced polyP levels in both mitochondria and the cytosol (Baev et al. 2016; Wang et al. 2016). The chain length of polyP in mammalian cells appears to be dependent on the cell type and physiological conditions, and ranges between 50 and 800 residues (Gabel and Thomas 1971; Kumble and Kornberg 1995). Studies on the specific polyP length distribution in the mammalian brain are slightly controversial, with some reports stating that brain cells contain predominantly long chains (800 mer) (Kumble and Kornberg 1995), whereas others found that the polyP chain lengths range between 10 and 100 phosphates (Lorenz et al. 1997; Stotz et al. 2014). These differences are likely because of variations in the experimental setups, and the challenges involved in selectively and quantitatively extracting different polyP chains from mammalian cells and tissues (Kornberg et al. 1999).
Factors that Alter polyP Levels in the Mammalian Brain

Quantitative analysis of polyP in mammalian tissues is challenging because of its low abundance (Kumble and Kornberg 1995; Kornberg et al. 1999), limiting the number of reports that have studied effectors of endogenous polyP levels. However, one study conducted in rats provided evidence that although total liver poly $\mathrm{P}$ levels stayed constant over time, total brain polyP levels appear to significantly change over the lifetime. The investigators found that polyP levels peak at 12 mo of age and then steadily decrease to about $50 \%$ of the maximal polyP levels by age 28 mo of the animal (Lorenz et al. 1997). This decrease was attributed to a specific loss in longchain polyPs $\left(150 \mathrm{P}_{\mathrm{i}}\right)$ and likely is the result of changes in endogenous exopolyphosphatase activity (Lorenz et al. 1997). If and how polyphosphatase activity or levels are regulated over the life span remains to be tested, as are other factors that could contribute to the loss of polyP. In addition, no information exists about the spatial and/or cell-type-specific distribution of polyP in the brain and whether all or only select regions undergo a loss in polyP over time. In addition to lifetime changes in brain polyP levels, certain pathological conditions appear to also alter polyP levels in the brain. For instance, it has been reported that the polyP levels in the brains of $\mathrm{AD}$ mice are significantly lower than the polyP levels in healthy, age-matched animals (Cremers et al. 2016). In a separate study, Angelova et al. (2014) detected increased amounts of polyP in cells with PD-related mutations. The fact that most familial forms of PD show mitochondrial dysfunction (Burchell et al. 2010a,b) correlates with previous findings that polyP levels are dependent on the energy status of mitochondria, and might explain the altered levels (Angelova et al. 2014).

Roles of polyP in the Mammalian Brain

polyP-A Structural and Functional Component of Channels and Pores

Early studies in bacteria revealed the unexpected finding that transformation-competent bacteria 
accumulate high levels of a membrane-spanning complex, consisting of the polymer polyhydroxybutyrate (PHB), short-to-medium chains of polyP, and $\mathrm{Ca}^{2+}$ (Reusch and Sadoff 1988). The precise structure of these channels is unknown but it has been proposed that by solvating $\mathrm{PHB}$, polyP might penetrate lipid bilayers and support the transport of divalent cations across the membrane (Reusch and Sadoff 1988; Castuma et al. 1995). The channels function as classical voltage-gated transporters on reconstitution into lipid bilayers (Reusch and Sadoff 1988; Castuma et al. 1995), and seem to play an important role in the transport of divalent metals such as $\mathrm{Ca}^{2+}$, as well as phosphate and DNA across bacterial membranes (Reusch and Sadoff 1988; Castuma et al. 1995). Soon after the discovery of $\mathrm{PHB}$-polyP-Ca ${ }^{2+}$ ion channels in bacteria, similar structures were identified in the rat liver mitochondria (Pavlov et al. 2005). These complexes, on their purification and reconstitution into lipid bilayers, were found to resemble the PTP, which is involved in $\mathrm{Ca}^{2+}$-mediated cell death (Crompton 1999; Rasola and Bernardi 2011). Indeed, depletion of mitochondrial polyP by the targeted overexpression of the yeast polyphosphatase PPX, significantly decreased mPTP opening and prevented ionomycin-induced cell death (Abramov et al. 2007). Conversely, treatment of astrocytes with exogenous polyP led to increased $\mathrm{mPTP}$ opening and cell death, an effect that was prevented by blocking PTP opening with cyclosporine A (Angelova et al. 2016). It is of note that only long-chain polyPs $\left(>120 \mathrm{P}^{\mathrm{i}}\right)$ appear to effectively induce mitochondrial depolarization by inhibition of respiration, opening of the MPTP, $\mathrm{Ca}^{2+}$ efflux, and activation of apoptosis (Angelova et al. 2016). More recently, polyP was also found to serve as a crucial structural and/or functional component of the pain-sensing transient receptor potential A1 (TRPA1) ion channel, expressed in sensory neurons (Kim and Cavanaugh 2007).

polyP-A Glio- and Neurotransmitter

In vivo studies indicated that polyP plays a central role in key homeostatic physiological activities, such as breathing, central sympathetic outflow, and the arterial blood pressure, suggesting that it plays a role as signaling molecule (Holmström et al. 2013). Although polyP has been reported to be primarily located in mitochondria, the nucleus, and lysosomes (Griffin et al. 1965; Pisoni and Lindley 1992; Kornberg 1995; Kumble and Kornberg 1995), astrocytes show a significant amount of polyP in cytoplasmic vesicle-like structures, which appear to be secreted through $\mathrm{Ca}^{2+}$-dependent exocytosis (Holmström et al. 2013; Stotz et al. 2014; Angelova et al. 2018) in a fashion similar to platelets and, potentially, bacteria (Müller et al. 2009; Sakatani et al. 2016). The secreted polyP can then be taken up by other astrocytes or neurons in which it has been shown to function as both a glio- and neurotransmitter, respectively (Holmström et al. 2013; Angelova et al. 2014). As a gliotransmitter, polyP appears to mediate communication between astrocytes through the binding to the $\mathrm{P} 2 \mathrm{Y} 1$ purinergic receptors, which leads to the activation of phospholipase $\mathrm{C}$, the activation of PIP2, and the induction of $\mathrm{Ca}^{2+}$ influx via IP3 from the endoplasmic reticulum (ER) (Dinarvand et al. 2014; Baev et al. 2016). This causes a depolarization of the cell, a further release of polyP from astrocytes, and the propagation of the signaling wave (Fig. 3) (Holmström et al. 2013; Dinarvand et al. 2014; Baev et al. 2016). This activity was shown irrespectively of the brain region or the chain length of polyP (Holmström et al. 2013). As a neurotransmitter, polyP was found to induce action potentials in both peripheral nervous system and central nervous system neurons by differentially modulating the function of neuronal voltage-dependent $\mathrm{Na}^{+}, \mathrm{K}^{+}$, and $\mathrm{Ca}^{2+}$ channels (Fig. 3) (Stotz et al. 2014; Baev et al. 2016). The finding that polyP serves as a neuroactive compound is supported by its presence in synaptosomes, in which it can be released on depolarization of the membrane potential by the addition of potassium chloride (Stotz et al. 2014).

\section{POLYPHOSPHATE-A GUARDIAN AGAINST AMYLOID CYTOTOXICITY}

Extensive work on elucidating the underlying mechanism of amyloid toxicity suggested that 


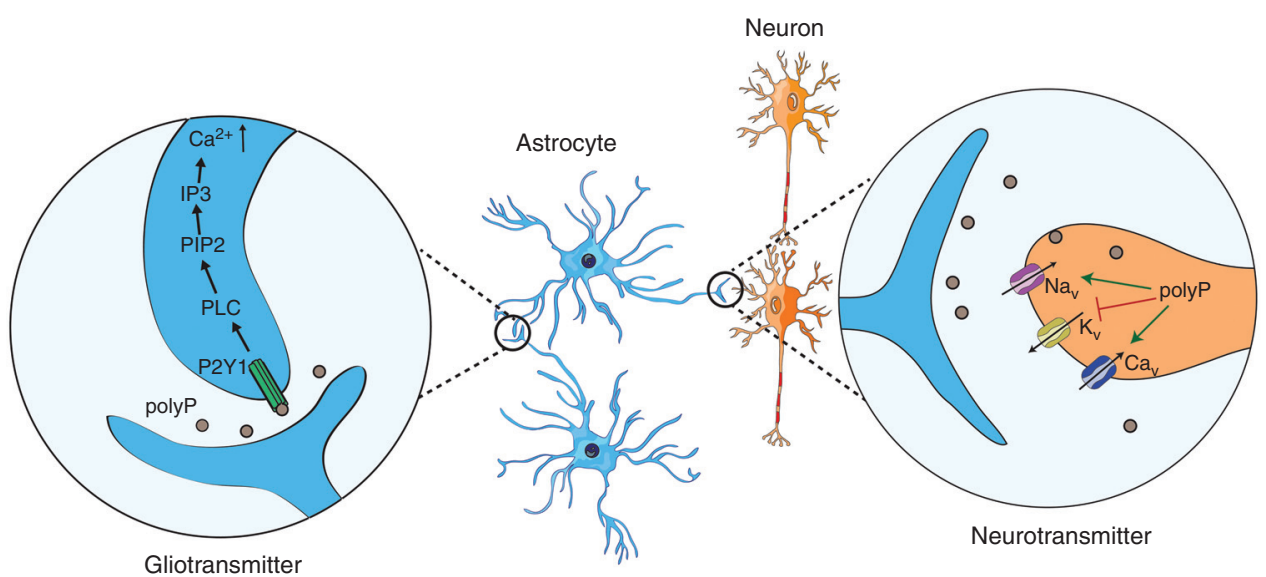

Figure 3. Polyphosphate ( polyP) acts as a glio- and neurotransmitter: Astrocytes release polyP that can be taken up either by other astrocytes or by neurons. In astrocytes (blue), polyP binds to and activates the P2Y1 purinergic receptor, causing, ultimately, an increase in intracellular $\mathrm{Ca}^{2+}$ levels. In neurons (orange), polyP increases action potential generation by influencing voltage-gated ion channels, blocking $\mathrm{K}_{\mathrm{v}}$ channels, sensitizing $\mathrm{N}_{\mathrm{av}}$ channels, and activating $\mathrm{C}_{\mathrm{av}}$ channels.

oligomers and/or protofibrils that accumulate in the pathway of fiber formation are the predominant species that causes neurotoxicity (Chen et al. 2015; Tipping et al. 2015). This is thought to be because of their ability to increase membrane permeability, alter mitochondrial function, and/or disrupt the cytoskeleton (Roberts and Brown 2015). Based on our observations that polyP substantially accelerates fiber formation in vitro, alters fiber morphology, and affects seeding and shedding behavior of the fibers, we examined the effect of polyP on amyloid toxicity. Indeed, we discovered that polyP protects differentiated SH-SY5Y cells against both $\alpha$-synuclein and $A \beta_{1-40 / 42}$ toxicity, and $A D$ mutants of Caenorhabditis elegans, through uptake of exogenous polyP, show a polyP-dependent delay in $\mathrm{A} \beta_{1-42}$-induced paralysis (Cremers et al. 2016). At this point, it is unclear how polyP affects the toxicity and how much of polyP action happens inside or outside of the cell (Holmström et al. 2013). A recent study confirmed these results using a different neuronal cell line, as well as primary cortical neurons, and showed that polyP protects cells against the neurotoxic effect of the $A \beta_{25-35}$ peptide (Müller et al. 2017). Because the administration of polyP was found to cause an increase in intracellular ATP levels, the investigators concluded that the presence of polyP reverses the $\beta$-amyloid-induced compromised energy status in neuronal cells and, in turn, abrogates the neurotoxic effect of $A \beta_{25-35}$ (Müller et al. 2017). Moreover, elimination of polyP from mitochondria via insertion of yeast PPX into the mitochondrial genome was found to protect brain cells from $\beta$-amyloid peptide toxicity, potentially, by increasing mitochondrial $\mathrm{Ca}^{2+}$ capacity and lowering the susceptibility of these cells to the PTP opening (Abramov et al. 2007). Independent of the precise mechanism of action, the evidence is convincing that polyP plays a role in amyloidogenic processes and protects cells against amyloid toxicity. Together with the observation that brain polyP levels decrease with age, as well as age-related pathological conditions, these results raise the exciting possibility that polyP acts as a physiological modifier of amyloidogenic processes.

\section{CONCLUDING REMARKS}

In 2006, 26.6 million people were affected by AD worldwide, and as a result of the dramatic increase in life expectancy, the prevalence is expected to quadruple by 2050 (Wimo et al. 2006; Brookmeyer et al. 2007). PD constitutes the 
J. Lempart and U. Jakob

second most common neurodegenerative disease affecting $1 \%-2 \%$ of the population above 60 years of age (Tanner and Goldman 1996). Current therapies are limited to treating the symptoms but not the cause of the diseases, and despite significant advances in the research field, many aspects of disease development remain unknown. In this review, we summarized recent findings that define polyP as a novel modulator of amyloidogenic processes and as a guardian against amyloid toxicity in cell culture. At this point, however, we do not know by what mechanism(s) polyP protects cells against amyloid toxicity or the extent to which these protective effects translate into the context of neurodegenerative diseases. Yet, the fact that age is the largest risk factor for neurodegenerative dis- eases, together with the finding that polyP levels in the brain decrease with age, prompts us to speculate about the potential roles of polyP in neurodegenerative diseases (Fig. 4).

It is possible that polyP protects against amyloid toxicity directly by modulating amyloid fibril formation, shedding, and seeding (Cremers et al. 2016). polyP present in the extracellular space might prevent the uptake of amyloid fibrils into and the transmission of amyloids between cells, thereby reducing toxicity and spreading of the disease (Brundin et al. 2010; Masuda-Suzukake et al. 2013; Steiner et al. 2018). Alternatively, endogenous polyP might segregate mature fibrils into inert compartments and/or increase the turnover of amyloids in the cell, thereby preventing dangerous concentra-

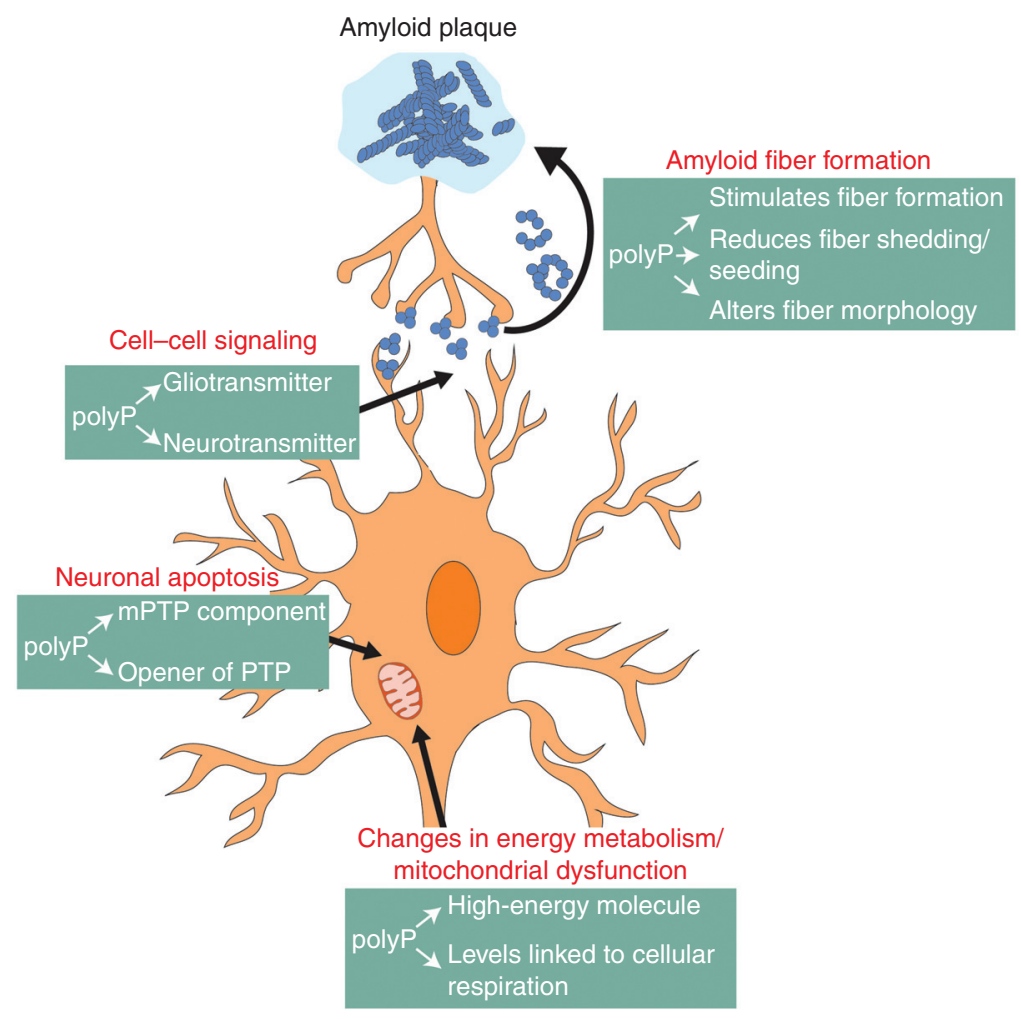

Figure 4. Processes that are directly or indirectly affected by amyloid fiber formation and contribute to neurodegeneration. Toxic oligomers and protofibrils, which form on the pathway from soluble amyloid monomers to insoluble fibers, have been shown to accumulate in the extracellular space, such as synapses in which they influence cell-cell communication or in cells in which they alter energy metabolism, cause mitochondrial dysfunction, and trigger apoptosis. Polyphosphate (polyP) has been shown to play critical roles in all of these processes. 
tions of toxic oligomers. It is also conceivable that polyP protects against amyloid toxicity through its roles in energy homeostasis and/or mitochondrial function (Baev et al. 2016; Wang et al. 2016). It is well known that AD is characterized by an impaired energy homeostasis of brain tissue (Müller et al. 2017) and most familiar forms of PD display mitochondrial dysfunction and changes in signal transition (Mounsey and Teismann 2010). Age- and/or disease-induced changes in polyP levels could make cells more vulnerable to mitochondrial dysfunction and organisms more prone to undergo neurodegeneration (Hernandez-Ruiz et al. 2006; Holmström et al. 2013; Stotz et al. 2014; Baev et al.2016). Until we have identified the system(s) responsible for polyP synthesis in mammalian cells, many of these ideas will remain speculations. However, as a physiological polymer used as a food additive and in cosmetics (Smith and Hong-Shum 2007; Müller et al. 2015a), polyP is considered to be safe for clinical applications (Tsutsumi et al. 2014; Müller et al. 2015b). Therefore, it is of great interest to further investigate the role of polyP in the development of neurodegenerative diseases, and identify whether the restoration of reduced polyP levels in aged brains would delay disease onset or progression.

\section{ACKNOWLEDGMENTS}

We thank Ellen Quarles for critically reading the manuscript and the members of the Jakob laboratory for many helpful discussions. Work that contributed to this review was supported by the National Institute of Health Grants GM065318 and GM116582. J.L. was funded by the PhD fellowship of the Boehringer Ingelheim Fonds (Stiftung fuer medizinische Grundlagenforschung).

\section{REFERENCES}

Abramov AY, Fraley C, Diao CT, Winkfein R, Colicos MA, Duchen MR, French RJ, Pavlov E. 2007. Targeted polyphosphatase expression alters mitochondrial metabolism and inhibits calcium-dependent cell death. Proc Natl Acad Sci 104: 18091-18096. doi:10.1073/ pnas.0708959104
Akiyama M, Crooke E, Kornberg A. 1992. The polyphosphate kinase gene of Escherichia coli. Isolation and sequence of the $p p k$ gene and membrane location of the protein. J Biol Chem 267: 22556-22561.

Akiyama M, Crooke E, Kornberg A. 1993. An exopolyphosphatase of Escherichia coli. The enzyme and its ppx gene in a polyphosphate operon. J Biol Chem 268: 633-639.

Angelova PR, Agrawalla BK, Elustondo PA, Gordon J, Shiba T, Abramov AY, Chang YT, Pavlov EV. 2014. In situ investigation of mammalian inorganic polyphosphate localization using novel selective fluorescent probes JC-D7 and JC-D8. ACS Chem Biol 9: 2101-2110. doi: $10.1021 / \mathrm{cb} 5000696$

Angelova PR, Baev AY, Berezhnov AV, Abramov AY. 2016. Role of inorganic polyphosphate in mammalian cells: From signal transduction and mitochondrial metabolism to cell death. Biochem Soc Trans 44: 40-45. doi:10.1042/ BST20150223

Angelova PR, Iversen KZ, Teschemacher AG, Kasparov S, Gourine AV, Abramov AY. 2018. Signal transduction in astrocytes: Localization and release of inorganic polyphosphate. Glia doi:10.1002/glia.23466

Azevedo C, Saiardi A. 2014. Functions of inorganic polyphosphates in eukaryotic cells: A coat of many colours. Biochem Soc Trans 42: 98-102. doi:10.1042/ BST20130111

Baev AY, Angelova PR, Abramov AY. 2016. Role of inorganic polyphosphate in the cells of the mammalian brain. In Inorganic polyphosphates in eukaryotic cells (ed. Kulakovskaya T, Pavlov E, Dedkova EN), pp. 115-121. Springer, New York.

Baldwin RL. 2008. Recollections of Arthur Kornberg (19182007) and the beginning of the Stanford Biochemistry Department. Protein Sci 17: 385-388. doi:10.1002/ pro.170385

Brookmeyer R, Johnson E, Ziegler-Graham K, Arrighi HM. 2007. Forecasting the global burden of Alzheimer's disease. Alzheimers Dement 3: 186-191. doi:10.1016/j. jalz.2007.04.381

Brown MR, Kornberg A. 2004. Inorganic polyphosphate in the origin and survival of species. Proc Natl Acad Sci 101: 16085-16087. doi:10.1073/pnas.0406909101

Bru S, Samper-Martin B, Quandt E, Hernandez-Ortega S, Martinez-Lainez JM, Gari E, Rafel M, Torres-Torronteras J, Marti R, Ribeiro MPC, et al. 2017. Polyphosphate is a key factor for cell survival after DNA damage in eukaryotic cells. DNA Repair (Amst) 57: 171-178. doi:10.1016/ j.dnarep.2017.08.001

Brundin P, Melki R, Kopito R. 2010. Prion-like transmission of protein aggregates in neurodegenerative diseases. Nat Rev Mol Cell Biol 11: 301-307. doi:10.1038/nrm2873

Burchell VS, Gandhi S, Deas E, Wood NW, Abramov AY, Plun-Favreau H. 2010a. Targeting mitochondrial dysfunction in neurodegenerative disease. Part I: Expert Opin Ther Targets 14: 369-385. doi:10.1517/147282210 03652489

Burchell VS, Gandhi S, Deas E, Wood NW, Abramov AY, Plun-Favreau H. 2010b. Targeting mitochondrial dysfunction in neurodegenerative disease. Part II: Expert Opin Ther Targets 14: 497-511. doi:10.1517/147282210 03730434 
J. Lempart and U. Jakob

Castuma CE, Huang R, Kornberg A, Reusch RN. 1995. Inorganic polyphosphates in the acquisition of competence in Escherichia coli. J Biol Chem 270: 12980-12983. doi:10.1074/jbc.270.22.12980

Chen W, Palmer RJ, Kuramitsu HK. 2002. Role of polyphosphate kinase in biofilm formation by Porphyromonas gingivalis. Infect Immun 70: 4708-4715. doi:10.1128/ IAI.70.8.4708-4715.2002

Chen SW, Drakulic S, Deas E, Ouberai M, Aprile FA, Arranz R, Ness S, Roodveldt C, Guilliams T, De-Genst EJ, et al. 2015. Structural characterization of toxic oligomers that are kinetically trapped during $\alpha$-synuclein fibril formation. Proc Natl Acad Sci 112: E1994-E2003. doi:10.1073/ pnas. 1421204112

Cremers CM, Knoefler D, Gates S, Martin N, Dahl JU, Lempart J, Xie L, Chapman MR, Galvan V, Southworth DR, et al. 2016. Polyphosphate: A conserved modifier of amyloidogenic processes. Mol Cell 63: 768-780. doi:10.1016/j. molcel.2016.07.016

Crompton M. 1999. The mitochondrial permeability transition pore and its role in cell death. Biochem J 341: 233249. doi:10.1042/bj3410233

Dahl JU, Gray MJ, Bazopoulou D, Beaufay F, Lempart J, Koenigsknecht MJ, Wang Y, Baker JR, Hasler WL, Young VB, et al. 2017. The anti-inflammatory drug mesalamine targets bacterial polyphosphate accumulation. Nat Microbiol 2: 16267. doi:10.1038/nmicrobiol.2016.267

Dinarvand P, Hassanian SM, Qureshi SH, Manithody C, Eissenberg JC, Yang L, Rezaie AR. 2014. Polyphosphate amplifies proinflammatory responses of nuclear proteins through interaction with receptor for advanced glycation end products and P2Y1 purinergic receptor. Blood 123: 935-945. doi:10.1182/blood-2013-09-529602

Docampo R, Jimenez V, King-Keller S, Li ZH, Moreno SN. 2011. The role of acidocalcisomes in the stress response of Trypanosoma cruzi. Adv Parasitol 75: 307-324. doi:10.1016/B978-0-12-385863-4.00014-9

Eichner T, Radford SE. 2011. A diversity of assembly mechanisms of a generic amyloid fold. Mol Cell 43: 8-18 doi:10.1016/j.molcel.2011.05.012

Feder ME, Hofmann GE. 1999. Heat-shock proteins, molecular chaperones, and the stress response: Evolutionary and ecological physiology. Annu Rev Physiol 61: 243282. doi:10.1146/annurev.physiol.61.1.243

Gabel NW, Thomas V. 1971. Evidence for the occurrence and distribution of inorganic polyphosphates in vertebrate tissues. J Neurochem 18: 1229-1242. doi:10.1111/ j.1471-4159.1971.tb00222.x

Gray MJ, Wholey WY, Wagner NO, Cremers CM, MuellerSchickert A, Hock NT, Krieger AG, Smith EM, Bender RA, Bardwell JC, et al. 2014. Polyphosphate is a primordial chaperone. Mol Cell 53: 689-699. doi:10.1016/j.molcel.2014.01.012

Griffin JB, Davidian NM, Penniall R. 1965. Studies of phosphorus metabolism by isolated nuclei. VII: Identification of polyphosphate as a product. J Biol Chem 240: 44274434.

Guerrero-Ferreira R, Taylor NM, Mona D, Ringler P, Lauer ME, Riek R, Britschgi M, Stahlberg H. 2018. Cryo-EM structure of $\alpha$-synuclein fibrils. eLife 7: e36402. doi:10.7554/eLife.36402
Hernandez-Ruiz L, Gonzalez-Garcia I, Castro C, Brieva JA, Ruiz FA. 2006. Inorganic polyphosphate and specific induction of apoptosis in human plasma cells. Haematologica 91: $1180-1186$.

Holmström KM, Marina N, Baev AY, Wood NW, Gourine AV, Abramov AY. 2013. Signalling properties of inorganic polyphosphate in the mammalian brain. Nat Commun 4: 1362. doi:10.1038/ncomms 2364

Hufnagel DA, Tukel C, Chapman MR. 2013. Disease to dirt: The biology of microbial amyloids. PLoS Pathog 9: e1003740. doi:10.1371/journal.ppat.1003740

Jimenez-Nunez MD, Moreno-Sanchez D, Hernandez-Ruiz L, Benitez-Rondan A, Ramos-Amaya A, Rodriguez-Bayona B, Medina F, Brieva JA, Ruiz FA. 2012. Myeloma cells contain high levels of inorganic polyphosphate which is associated with nucleolar transcription. Haematologica 97: 1264-1271. doi:10.3324/haematol.2011.051409

Kampinga HH. 2014. Chaperoned by prebiotic inorganic polyphosphate molecules: An ancient transcription-independent mechanism to restore protein homeostasis. $\mathrm{Mol}$ Cell 53: 685-687. doi:10.1016/j.molcel.2014.02.023

Kawazoe Y, Shiba T, Nakamura R, Mizuno A, Tsutsumi K, Uematsu T, Yamaoka M, Shindoh M, Kohgo T. 2004. Induction of calcification in MC3T3-E1 cells by inorganic polyphosphate. J Dent Res 83: 613-618. doi:10.1177/ 154405910408300806

Kim D, Cavanaugh EJ. 2007. Requirement of a soluble intracellular factor for activation of transient receptor potential A1 by pungent chemicals: Role of inorganic polyphosphates. J Neurosci 27: 6500-6509. doi:10.1523/ jneurosci.0623-07.2007

Kornberg A. 1995. Inorganic polyphosphate: Toward making a forgotten polymer unforgettable. J Bacteriol 177: 491-496. doi:10.1128/jb.177.3.491-496.1995

Kornberg A, Kornberg SR, Simms ES. 1956. Metaphosphate synthesis by an enzyme from Escherichia coli. Biochim Biophys Acta 20: 215-227. doi:10.1016/0006-3002(56) 90280-3

Kornberg A, Rao NN, Ault-Riché D. 1999. Inorganic polyphosphate: A molecule of many functions. Annu Rev Biochem 68: 89-125. doi:10.1146/annurev.biochem.68.1.89

Kulaev IS, Vagabov VM. 1983. Polyphosphate metabolism in micro-organisms. Adv Microb Physiol 24: 83-171. doi:10.1016/S0065-2911(08)60385-9

Kulakovskaya TV, Vagabov VM, Kulaev IS. 2012. Inorganic polyphosphate in industry, agriculture and medicine: Modern state and outlook. Process Biochem 47: 1-10. doi:10.1016/j.procbio.2011.10.028

Kumble KD, Kornberg A. 1995. Inorganic polyphosphate in mammalian cells and tissues. J Biol Chem 270: 58185822. doi:10.1074/jbc.270.11.5818

Lorenz B, Munkner J, Oliveira MP, Kuusksalu A, Leitao JM, Muller WE, Schroder HC. 1997. Changes in metabolism of inorganic polyphosphate in rat tissues and human cells during development and apoptosis. Biochim Biophys Acta 1335: 51-60. doi:10.1016/S0304-4165(96)00121-3

Masuda-Suzukake M, Nonaka T, Hosokawa M, Oikawa T, Arai T, Akiyama H, Mann DM, Hasegawa M. 2013. Prion-like spreading of pathological $\alpha$-synuclein in brain. Brain 136: 1128-1138. doi:10.1093/brain/awt037 
Montilla M, Hernandez-Ruiz L, Garcia-Cozar FJ, AlvarezLaderas I, Rodriguez-Martorell J, Ruiz FA. 2012. Polyphosphate binds to human von Willebrand factor in vivo and modulates its interaction with glycoprotein $\mathrm{Ib}$. J Thromb Haemost 10: 2315-2323. doi:10.1111/jth.12004

Morrissey JH, Choi SH, Smith SA. 2012. Polyphosphate: An ancient molecule that links platelets, coagulation, and inflammation. Blood 119: 5972-5979. doi:10.1182/ blood-2012-03-306605

Mounsey RB, Teismann P. 2010. Mitochondrial dysfunction in Parkinson's disease: Pathogenesis and neuroprotection. Parkinsons Dis 2011: 617472

Müller F, Mutch NJ, Schenk WA, Smith SA, Esterl L, Spronk HM, Schmidbauer S, Gahl WA, Morrissey JH, Renne T. 2009. Platelet polyphosphates are proinflammatory and procoagulant mediators in vivo. Cell 139: 1143-1156. doi:10.1016/j.cell.2009.11.001

Müller WE, Tolba E, Schroder HC, Diehl-Seifert B, Wang X. 2015a. Retinol encapsulated into amorphous $\mathrm{Ca}^{2+}$ polyphosphate nanospheres acts synergistically in MC3T3-E1 cells. Eur J Pharm Biopharm 93: 214-223. doi:10.1016/j. ejpb.2015.04.005

Müller WEG, Tolba E, Schröder HC, Wang S, Glaßer G, Muñoz-Espí R, Link T, Wang X. 2015b. A new polyphosphate calcium material with morphogenetic activity. Materials Lett 148: 163-166. doi:10.1016/j.matlet. 2015.02.070

Müller WEG, Wang S, Ackermann M, Neufurth M, Steffen R, Mecja E, Munoz-Espi R, Feng Q, Schroder HC, Wang X. 2017. Rebalancing $\beta$-amyloid-induced decrease of ATP Level by amorphous nano/micro polyphosphate: Suppression of the neurotoxic effect of amyloid $\beta$-protein fragment 25-35. Int J Mol Sci 18: E2154. doi:10.3390/ ijms18102154

Paulsen CE, Armache JP, Gao Y, Cheng Y, Julius D. 2015. Structure of the TRPA1 ion channel suggests regulatory mechanisms. Nature 520: 511-517. doi:10.1038/nature 14367

Pavlov E, Zakharian E, Bladen C, Diao CT, Grimbly C, Reusch RN, French RJ. 2005. A large, voltage-dependent channel, isolated from mitochondria by water-free chloroform extraction. Biophys J 88: 2614-2625. doi:10.1529/ biophysj.104.057281

Pisoni RL, Lindley ER. 1992. Incorporation of $\left.{ }^{32} \mathrm{P}\right]$ orthophosphate into long chains of inorganic polyphosphate within lysosomes of human fibroblasts. J Biol Chem 267: 3626-3631.

Rao NN, Gómez-García MR, Kornberg A. 2009. Inorganic polyphosphate: Essential for growth and survival. Annu Rev Biochem 78: 605-647. doi:10.1146/annurev.bio chem.77.083007.093039

Rashid MH, Rao NN, Kornberg A. 2000a. Inorganic polyphosphate is required for motility of bacterial pathogens. $J$ Bacteriol 182: 225-227. doi:10.1128/JB.182.1.225227.2000

Rashid MH, Rumbaugh K, Passador L, Davies DG, Hamood AN, Iglewski BH, Kornberg A. 2000b. Polyphosphate kinase is essential for biofilm development, quorum sensing, and virulence of Pseudomonas aeruginosa. Proc Natl Acad Sci 97: 9636-9641. doi:10.1073/pnas.170283397

Rasola A, Bernardi P. 2011. Mitochondrial permeability transition in $\mathrm{Ca}^{2+}$-dependent apoptosis and necrosis.
Cell Calcium 50: 222-233. doi:10.1016/j.ceca.2011.04. 007

Reusch RN, Sadoff HL. 1988. Putative structure and functions of a poly- $\beta$-hydroxybutyrate/calcium polyphosphate channel in bacterial plasma membranes. Proc Natl Acad Sci 85: 4176-4180. doi:10.1073/pnas.85.12. 4176

Roberts HL, Brown DR. 2015. Seeking a mechanism for the toxicity of oligomeric $\alpha$-synuclein. Biomolecules 5: 282 305. doi: $10.3390 /$ biom 5020282

Sakatani A, Fujiya M, Ueno N, Kashima S, Sasajima J, Moriichi K, Ikuta K, Tanabe H, Kohgo Y. 2016. Polyphosphate derived from Lactobacillus brevis inhibits colon cancer progression through induction of cell apoptosis. Anticancer Res 36: 591-598.

Seidlmayer LK, Gomez-Garcia MR, Blatter LA, Pavlov E, Dedkova EN. 2012. Inorganic polyphosphate is a potent activator of the mitochondrial permeability transition pore in cardiac myocytes. J Gen Physiol 139: 321-331. doi:10.1085/jgp.201210788

Smith J, Hong-Shum L. 2007. Sodium polyphosphate. In Food additives databook. Wiley, Hoboken, NJ.

Smith SA, Morrissey JH. 2008. Polyphosphate enhances fibrin clot structure. Blood 112: 2810-2816. doi:10.1182/ blood-2008-03-145755

Smith SA, Mutch NJ, Baskar D, Rohloff P, Docampo R, Morrissey JH. 2006. Polyphosphate modulates blood coagulation and fibrinolysis. Proc Natl Acad Sci 103: 903908. doi:10.1073/pnas. 0507195103

Smith SA, Choi SH, Davis-Harrison R, Huyck J, Boettcher J, Rienstra CM, Morrissey JH. 2010. Polyphosphate exerts differential effects on blood clotting, depending on polymer size. Blood 116: 4353-4359. doi:10.1182/blood2010-01-266791

Soto C. 2003. Unfolding the role of protein misfolding in neurodegenerative diseases. Nat Rev Neurosci 4: 49-60. doi:10.1038/nrn1007

Steiner JA, Quansah E, Brundin P. 2018. The concept of $\alpha$-synuclein as a prion-like protein: Ten years after. Cell Tissue Res 373: 161-173. doi:10.1007/s00441-0182814-1

Stotz SC, Scott LO, Drummond-Main C, Avchalumov Y, Girotto F, Davidsen J, Gómez-Gárcia MR, Rho JM, Pavlov EV, Colicos MA. 2014. Inorganic polyphosphate regulates neuronal excitability through modulation of voltage-gated channels. Mol Brain 7: 42. doi:10.1186/1756-66067-42

Taglialegna A, Lasa I, Valle J. 2016. Amyloid structures as biofilm matrix scaffolds. J Bacteriol 198: 2579-2588. doi:10.1128/JB.00122-16

Tanner CM, Goldman SM. 1996. Epidemiology of Parkinson's disease. Neurol Clin 14: 317-335. doi:10.1016/ S0733-8619(05)70259-0

Tipping KW, Karamanos TK, Jakhria T, Iadanza MG, Goodchild SC, Tuma R, Ranson NA, Hewitt EW, Radford SE. 2015. pH-induced molecular shedding drives the formation of amyloid fibril-derived oligomers. Proc Natl Acad Sci 112: 5691-5696. doi:10.1073/pnas.14231 74112

Tsutsumi K, Saito N, Kawazoe Y, Ooi HK, Shiba T. 2014. Morphogenetic study on the maturation of osteoblastic 
J. Lempart and U. Jakob

cell as induced by inorganic polyphosphate. PLOS ONE 9: e86834. doi:10.1371/journal.pone.0086834

Wang X, Schroder HC, Muller WE. 2016. Polyphosphate as a metabolic fuel in Metazoa: A foundational breakthrough invention for biomedical applications. Biotechnol J 11: 11-30. doi:10.1002/biot.201500168

Whyte CS, Chernysh IN, Domingues MM, Connell S, Weisel JW, Ariens RA, Mutch NJ. 2016. Polyphosphate delays fibrin polymerisation and alters the mechanical properties of the fibrin network. Thromb Haemost 116: 897-903. doi:10.1160/TH16-01-0062

Wimo A, Jonsson L, Winblad B. 2006. An estimate of the worldwide prevalence and direct costs of dementia in 2003. Dement Geriatr Cogn Disord 21: 175-181. doi:10.1159/000090733

Wood HG, Clark JE. 1988. Biological aspects of inorganic polyphosphates. Annu Rev Biochem 57: 235-260. doi:10.1146/annurev.bi.57.070188.001315

Yoo NG, Dogra S, Meinen BA, Tse E, Haefliger J, Southworth DR, Gray MJ, Dahl JU, Jakob U. 2018. Polyphosphate stabilizes protein unfolding intermediates as soluble amyloid-like oligomers. J Mol Biol 430: 4195-4208. doi:10.1016/j.jmb.2018.08.016

Zakharian E, Thyagarajan B, French RJ, Pavlov E, Rohacs T. 2009. Inorganic polyphosphate modulates TRPM8 channels. PLoS ONE 4: e5404. doi:10.1371/journal.pone.0005404 


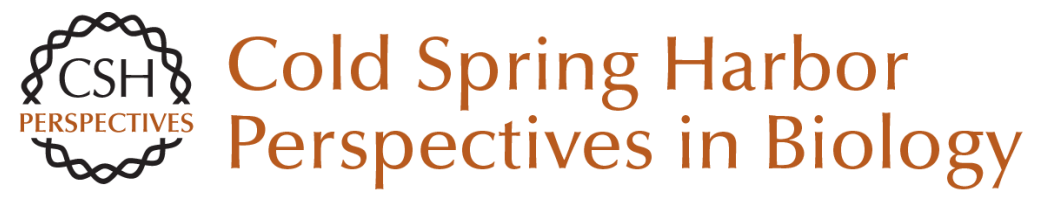

\section{Role of Polyphosphate in Amyloidogenic Processes}

Justine Lempart and Ursula Jakob

Cold Spring Harb Perspect Biol 2019; doi: 10.1101/cshperspect.a034041 originally published online January 7, 2019

\section{Subject Collection Protein Homeostasis}

Proteome-Scale Mapping of Perturbed

Proteostasis in Living Cells

Isabel Lam, Erinc Hallacli and Vikram Khurana

Pharmacologic Approaches for Adapting Proteostasis in the Secretory Pathway to

Ameliorate Protein Conformational Diseases Jeffery W. Kelly

Cell-Nonautonomous Regulation of Proteostasis in Aging and Disease

Richard I. Morimoto

The Autophagy Lysosomal Pathway and

Neurodegeneration

Steven Finkbeiner

Functional Modules of the Proteostasis Network Gopal G. Jayaraj, Mark S. Hipp and F. Ulrich Hartl

Protein Solubility Predictions Using the CamSol Method in the Study of Protein Homeostasis Pietro Sormanni and Michele Vendruscolo

Recognition and Degradation of Mislocalized

Proteins in Health and Disease

Ramanujan S. Hegde and Eszter Zavodszky

The Nuclear and DNA-Associated Molecular Chaperone Network

Zlata Gvozdenov, Janhavi Kolhe and Brian C. Freeman
The Amyloid Phenomenon and Its Significance in Biology and Medicine

Christopher M. Dobson, Tuomas P.J. Knowles and Michele Vendruscolo

A Chemical Biology Approach to the Chaperome

in Cancer--HSP9O and Beyond

Tony Taldone, Tai Wang, Anna Rodina, et al.

Proteostasis in Viral Infection: Unfolding the Complex Virus-Chaperone Interplay

Ranen Aviner and Judith Frydman

The Proteasome and Its Network: Engineering for Adaptability Daniel Finley and Miguel A. Prado

Functional Amyloids Daniel Otzen and Roland Riek

Chaperone Interactions at the Ribosome Elke Deuerling, Martin Gamerdinger and Stefan G. Kreft

Mechanisms of Small Heat Shock Proteins Maria K. Janowska, Hannah E.R. Baughman, Christopher N. Woods, et al.

Structure, Function, and Regulation of the Hsp90 Machinery

Maximilian M. Biebl and Johannes Buchner

For additional articles in this collection, see http://cshperspectives.cshlp.org/cgi/collection/

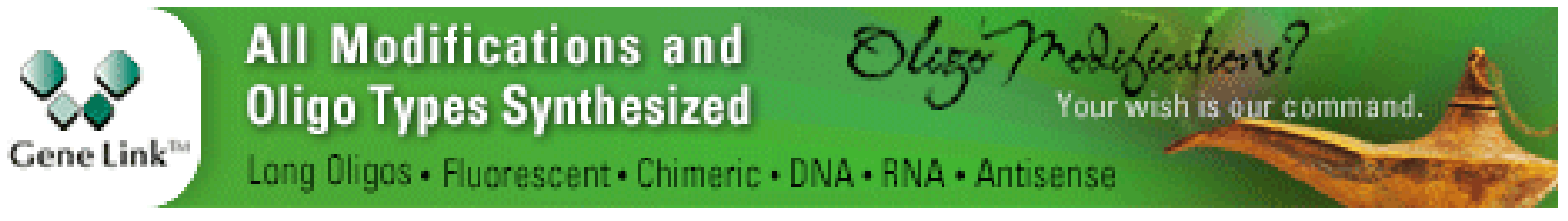


For additional articles in this collection, see http://cshperspectives.cshlp.org/cgi/collection/

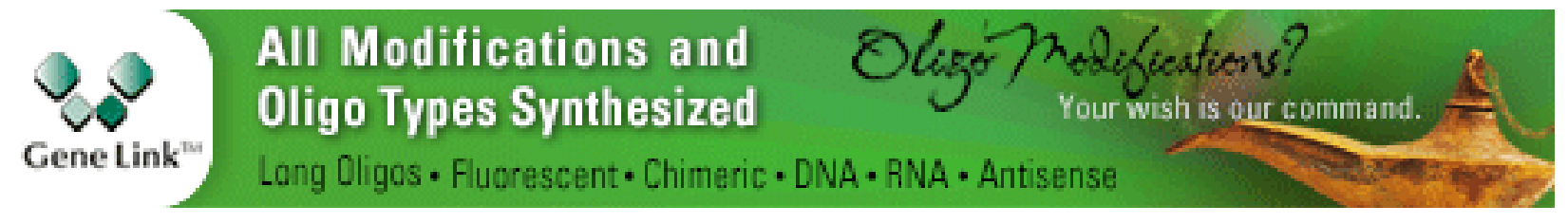

Copyright @ 2019 Cold Spring Harbor Laboratory Press; all rights reserved 